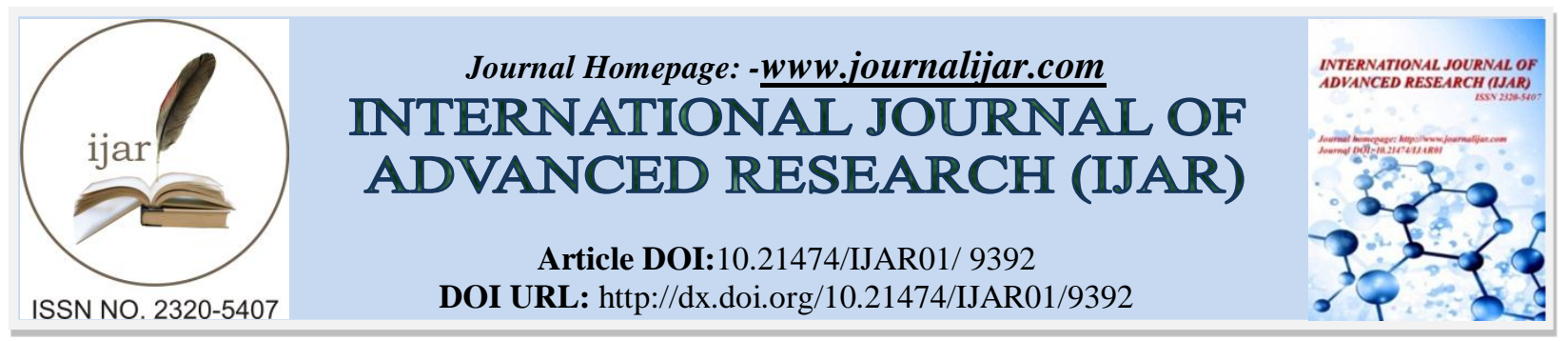

RESEARCH ARTICLE

\title{
ADULT KAPOSIFORM HEMANGIOENDOTHELIOMA OF THE LEG COMPLICATED BY KASABAKH MERITT PHENOMENON.
}

Yassamina Ribag, Lahcen Khalfi, Kamal Fiqhi, Adil Ouardi, Issam MokfiI and Karim Elkhatib. Departement of stomatology and plastic surgery. Mohamed V teaching Armed Forced Hospital. Rabat.

\section{Manuscript Info}

\section{Manuscript History}

Received: 15 May 2019

Final Accepted: 17 June 2019

Published: July 2019

Key words:-

Adult, Kaposiform

hemangiendothelioma, Kasabach-Merritt phenomenon, surgery, Case report.

\begin{abstract}
Kaposiform hemangioendothelioma is a rare, locally aggressive vascular neoplasm that mainly occurs during childhood . the tumor is often located on the skin but may be deeper.

The development of KHE in adults is very rare, and its evolution towards KMP is exceptional.

The KMP is defined as the combination of a deep thrombocytopenia and a vascular tumor, usually a KHE or a tuftted angioma.

It is a life threatening pathology, because of the major risk of bleeding, and compression of vital structure. A multidisciplinary approach to treatment has to be employed.
\end{abstract}

Copy Right, IJAR, 2019,. All rights reserved.

\section{Introduction:-}

Kaposiform hemangioendothelioma (KHE) is a very rare vascular neoplasm. It occurs mostly in children and is rarely observed in adults. It is locally aggressive and is commonly associated with Kasabakh Meritt Phenomenon (KMP). $(1,2)$

Kasabach-Merritt Syndrome (KMS) is a rare and potentially lifethreatening phenomenon characterized by the association of a vascular tumor, either a kaposiform hemangioendothelioma or a tufted angioma, and thrombocytopenic coagulapathy occurring in an infant (3)

The diagnosis of KHE is made on the basis of clinical presentation and standard pathologic examination, including immunohistochemical studies and imaging.

Many treatment modalities are available for KHE, including surgery, radiation therapy, pharmacologic treatment, angiography and embolization.

We present a very rare case of a 87 year old man with KHE of the right leg complicated by KMP.

We believe that it's one of the first report of adult-onset $\operatorname{KHE}$ associated with $\operatorname{KMP}(4,5)$

Case presentation :

A 87-year-old man, with a past medical history consistent of hypertension, diabetes and transurethral resection of prostate, presented with a cutaneous lesion in his left leg due to a neglected trauma.

Corresponding Author:-Yassamina Ribag.

Address:-Departement of stomatology and plastic surgery. Mohamed V teaching Armed Forced 
The lesion was in the middle third of the anterior side of his right leg. It was painless, bleeding on contact and gradually increasing in size.

Clinnicaly, the tumor was ulcero-budding, blackish, firm and measuring about $8 \mathrm{~cm} \times 10 \mathrm{~cm}$. (fig1)

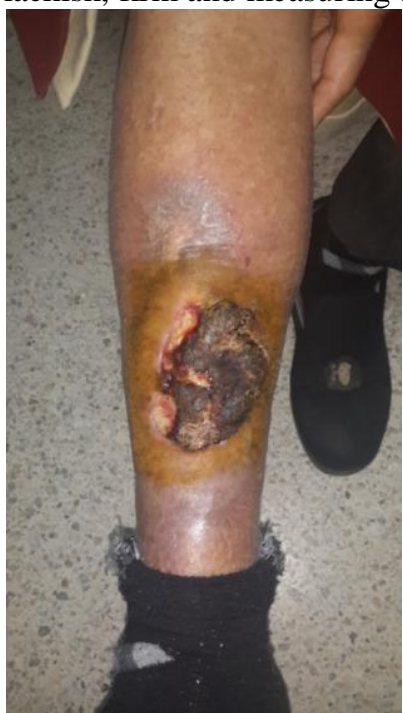

Fig 1:-anteriour view of the tumor

\section{Standard X-ray of leg bones showed tibial infiltration}

An angioTDM of the leg objectified a vascular tumor with cortical hyperostosis of the tibia. The platelet count achieved during this period was 273,000 plqt: $\mathrm{mm} 3$.
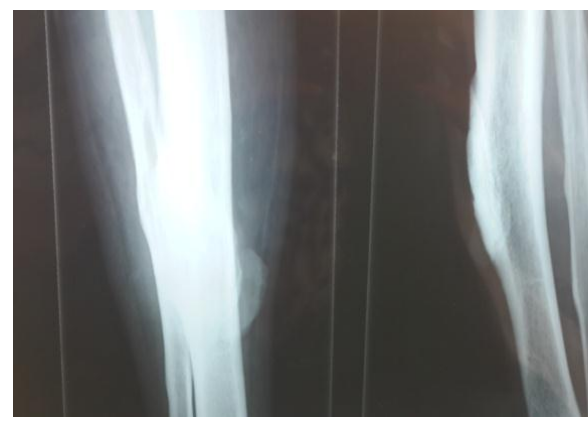

Fig 2:-standard x-ray

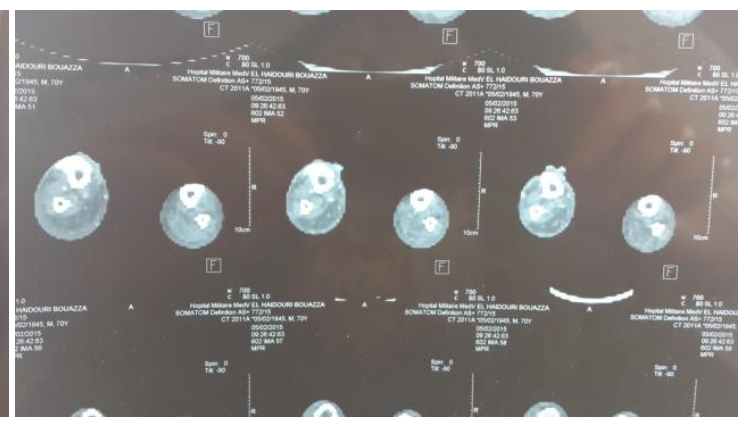

Fig 3:-Angio TDM : vascular tumor and corticall hyperostosis

We performed a wide excision of the tumor with lateral margins of more than $1 \mathrm{~cm}$ and a deep margin carrying even the infiltrated part of the tibia. 


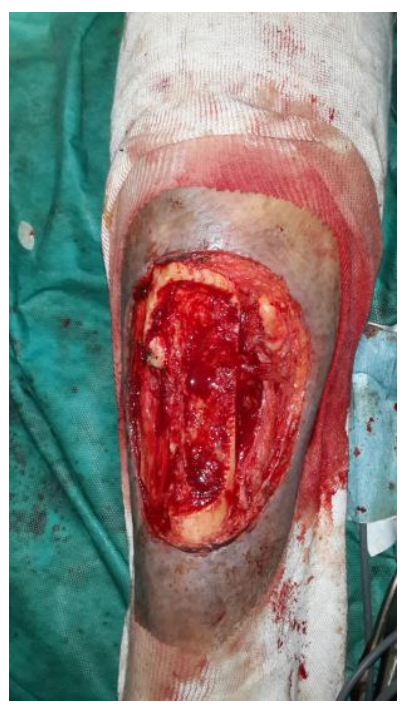

Fig 4:-excision of the tumor

Anatomopathological examination of the surgical piece has revealed KHE and confirmed that the lateral and deep limits were non pathological at about $1 \mathrm{~cm}$.
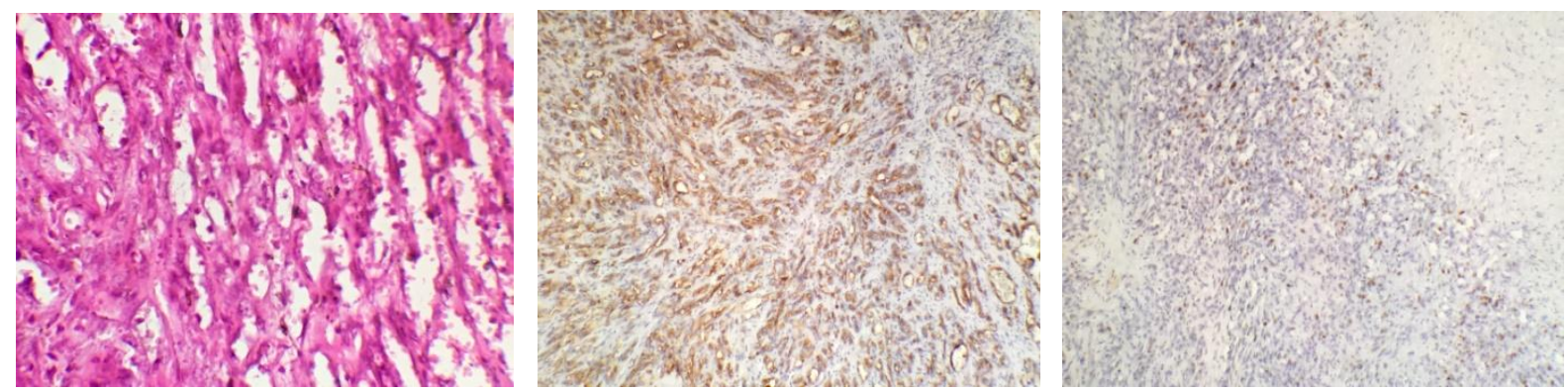

Fig 5:-Histological features of the surgical piece.

a : view of KHE shows Clustering of capillaries and spindle cell nodules

$\mathrm{b}$ : Immunohistochemical staining for CD34 is positive

c : Immunohistochemical staining for HHV8 is positive

Then we completed the surgery, by covering the loss of sustance by two flaps and a skin graft.

The patient was followed up for several months without recidivism, then he was lost. 

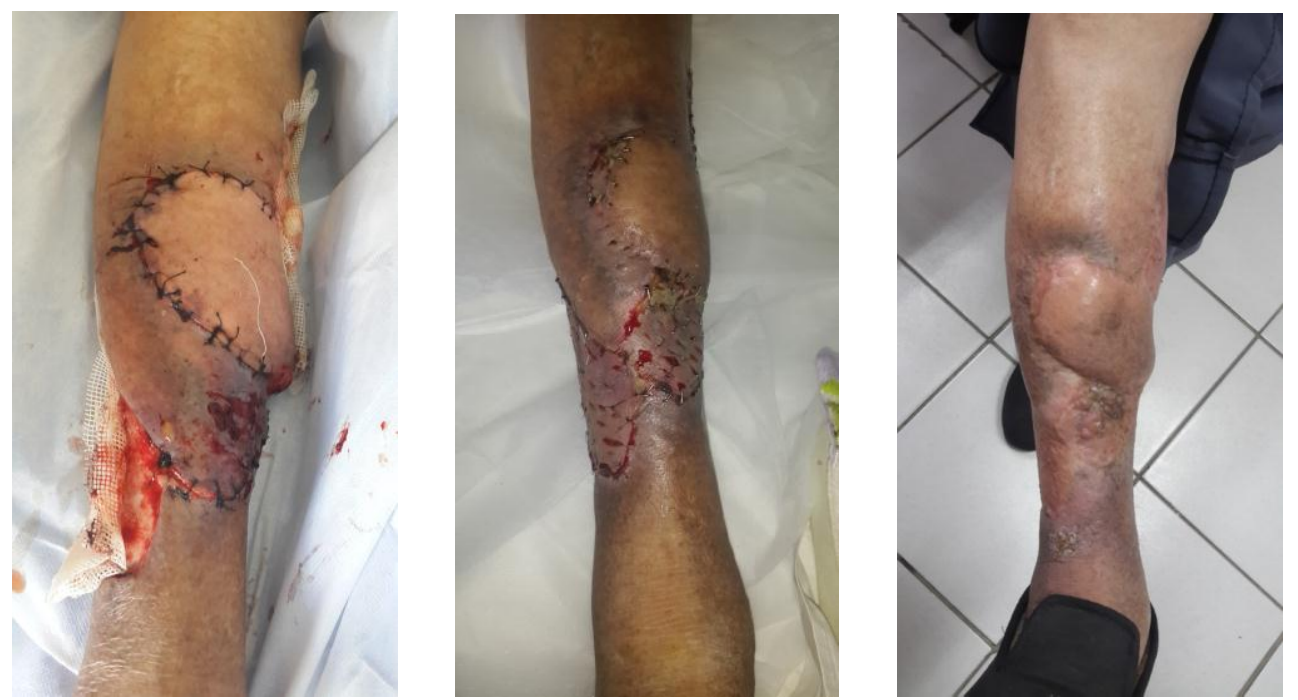

Fig 6:-the loss of substance was covered by two flaps and skin graft.

One day he presented to the emergency department. It was noted the presence of multiple nodules developed in the previous surgical site. The tumor mass was painless, immobile and sizing $12 \times 6 \times 5 \mathrm{~cm}$. The overlying skin was deep red-purple and bleeding spontaneously with ecchymosis over and around the tumor.

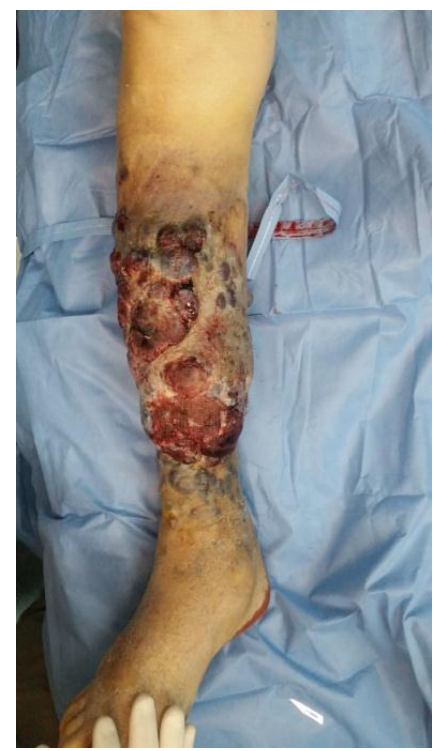

Fig 7:-view of the tumor showing multiple nodules red-purple and ecchymosis over and around

Laboratory results demonstrated platelet count $24.000 / \mathrm{mm} 3$, normocytic normochromic anemia with hemoglobin $6.3 \mathrm{~g} / \mathrm{dl}$, hematocrit $26 \% 1$.

The coagulation tests were: prothrombin time of $12.9 \mathrm{~s} \mathrm{(11} \mathrm{to} 13.5 \mathrm{~s}$ ), plasma fibrinogen concentration of $2.70 \mathrm{~g} / \mathrm{l}$ ((normal 1.50-3.87 g/L)), and moderate increase in D-dimer $1.2 \mu \mathrm{g} / \mathrm{mL}(<0.5 \mu \mathrm{g} / \mathrm{mL})$.

Bleeding was not controlled despite compression dressing over the lesion and the transfusion of packed RBCs (04units) and platelet concentrates (10 units). Methylprednisolone was injected intravenously $(5 \mathrm{mg} / \mathrm{kg}$ ) but no further improvement in platelets or hemoglobin was observed.

The case has been discussed in a multidisciplinary setting including hematologist, plastic surgeon and anesthesiologist. 
In the absence of other alternatives, it was decided to perform a transfemoral amputation of the right leg.

Platelet count rapidly had increased to $66.000 / \mathrm{mm} 3$ and hemoglobin had improved to $10,3 \mathrm{~g} / \mathrm{dl}$, no bleeding of incisional wound was observed.

In the second post-operative day, his report showed platelet count of $115.000 / \mathrm{mm} 3$.

His follow up was uneventful.

\section{Discussion:-}

Kaposiform hemangioendothelioma (KHE) is a rare borderline vascular tumor with locally aggressive behavior. It was first described in 1993 by Zukerberg,and al, it presents common features to both hemangiomas and Kaposi's sarcoma $(1,2)$.

It usually occurs in newborns or infants less than 6 months (3) and rarely in adults.

Fernandes and all, reviewed all the articles talking about HEK and KMP and published in Pub Med, from April 1993 to July 2007, he found that only 20 adults were recorded $(2,6,7,8,9,10,11,12,13)$

Since then, some other cases, about twelve, have been described all over the world. $(14,15,16,17,18,19,20,21$, 22)

The KHE has got two clinical presentations : cutaneous and visceral. $(2,3,8,13,15,16,22)$.

Cutaneous KHE adopts a characteristic violet color and typically grows in an aggressive infiltrative manner involving the underlying skin, most commonly as a superficial or deep soft tissue mass on the extremities $(1,23)$ and trunk. $(1,15,20)$.

It is a badly limited lesion, indurated, often hot; it was the case of our patient.

The visceral form is essentially retro-peritoneal (1) and can affect vital organs: intestine, liver (17), spleen (22), and also cervico-thoracic: tongue (14), mediastinum (24), thymus, lung...

Other localisations have been described, such as: bone, sinus (21), testiculs (19), and breast (18).

KHE is usually a solitary tumor (1), some cases of multifocal HEK have been recorded (24).

The cellular area of this tumor is mainly composed of infiltrating lobulated nodules with slitlike or crescentic vessels which are poorly canalized and lined by spindle shaped endothelial cells. The tumor partially contains glomeruloid structures and capillary hemangioma-like structures with clear vascular cavities. Immunohistochemical staining for CD34 and proxy 1 are positive. $(1,13,15,22,24,25,26)$.

In our case, the histological exam demonstred the same things: spindle cells with irregular bundle pattern and slit like vascular cavities. Immunohistochemical staining for CD34 was positive.

The value of radiologic imaging, including computed tomography or ultrasonography, in patients with KHE is unclear because of a paucity of reports.

Doppler ultrasounds show the KHE as a badly limited mass with variable echogenicity, vascular density and sometimes presence of calcifications.

Magnetic resonance imaging is the imaging modality of choice in KHE, it helps to evaluate the evolution and tumoral extension (18). The KHE appears like an heterogeneous mass, iso to hypoT1, hyperT2, infiltrating the subcutaneous fat, destructing and remodeling the adjacent bone $(1,27,28,29)$

These results are quite similar to ours. 
Wide surgical excision of KHE seemed to be its radical and definitive treatment according to the literature $(2,30)$, unfortunately, this was not our patient s case. Despite the oncological excision, surgery could not prevent recurrence of the tumor and its progression to KM P.

The evolution of KHE is fast and does not tend to regress spontaneously, if not treated it could evolve to KASABAKH MERITT Phenomenon (3).

Kasabach-Merritt syndrome (KMP) was first noted by Kasabach and Merritt in 1940 when they described a newborn male baby with a rapidly enlarging capillary hemangioma in association with increasing extensive purpura of the skin and thrombocytopenia.

KMS is characterized by a rapidly enlarging vascular anomaly and consumptive coagulopathy with thrombocytopenia, a prolonged prothrombin time, a partial thromboplastin time, hypofibrinogenemia, and the presence of D-dimer and fibrin split products, with or without microangiopathic hemolytic anemia $(3,31)$.

The mechanism for consumption coagulapathy of KMP is thought to be platelet trapping by the tumor, it is due to the interaction between abnormally proliferating endothelium within the hemangioma and the platelets, which leads to the activation of platelets and a secondary activation of coagulation cascades and the consumption of various clotting factors (31).

In practice most KMP occurs before the age of 6 months, it is exceptional in adults.

The literature remains poor on this subject, only one case was found, it was published in 2008, it was the case of an 85-year-old woman presenting with an angioma of the liver (17). Of 20 adult patients studied by Fernandes, no one developed a PKM (2). In a review of the literature conducted in 2016 by Vashi, on 20 articles about HEK in adults, from 2000 to 2014, no case of PKM was found (14).

The management of KMP must be multidisciplinary including surgeons, anestesist, hematologist... and must have two goals: the control of coagulopathy and the eradication of the vascular tumor. (3)

The administration of fresh frozen plasma, packed RBCs and platelets concentrate is indicated in cases of haemorrhage or if a surgical procedure is considered (30).

Surgical excision of the tumor appears to be the most effective treatment of the $\operatorname{KMP}(1,30,31)$ Tumor embolization, radiotherapy, laser, cryotherapy, high dose systemic corticosteroids, interferon alpha $2 \mathrm{a}$ or $2 \mathrm{~b}$, vincristine, antiplatelet agents, antifibrinolytics, and propanolol are all treatments that can be proposed in the PKM, indicated alone or associated, depending on the doctor's habits and on the treatment availability. $(32,33,34,35)$

More recent and promising treatment is sirolimus (36). Sirolimus has been described to decrease tumor burden and to cause cell apoptosis.

Because of the imminently life-threatening tumor, we estimated that the time to respond to these medical therapies is considered too long and consequently they were not an option. In addition, the effectiveness of these treatments has been inconsistent and currently, there are no known treatment guidelines.

Transarterial embolization is an effective therapeutic option specially in case of unresectable tumor due to its large size and infiltrating nature (31).

Unfortunately, this option was not available in our hospital at the time of admission.

\section{Conclusion:-}

KMP is a very rare tumor in adults, only one case was found on literature. There are no guidelines of its treatement. Howeever, surgery seems to be the most effective. 


\section{Références:-}

1. Zukerberg LR, Nickoloff BJ, Weiss SW. Kaposiform hemangioendothelioma of infancy and childhood: an aggressive neoplasm associated with Kasabach-Merritt syndrome and lymphangiomatosis. Am J Surg Pathol $1993 ; 17: 321-8$.

2. Y. Fernández, M. Bernabeu-Wittel, J.S. García-Morillo. Kaposiform hemangioendothelioma :European Journal of Internal Medicine 20 (2009) 106-113.

3. P. LE NOUAIL, V. VISEUX, O. ENJOLRAS. Phénomène de Kasabach-Merritt: Ann Dermatol Venereol 2007;134:580-6.

4. C. Mallaret, M. Planchet, J. Ramaniraka, H. Savini, R. Saidi, P. Le Bougeant, S. Molinier. Syndrome de Kasabach-Merritt et angiome hépatique géant chez l'adulte. 10.1016/j.revmed.2008.10.301

5. Allan M. Concejero, Chao-Long Chen, Tai-Yi Chen, Hock-Liew Eng, and Fang-Ying Kuo, Kaohsiung, Giant cavernous hemangioma of the liver with coagulopathy: Adult Kasabach-Merritt syndrome. Surgery February 2009 ; Volume 145, Number $2 ; 245-7$.

6. Cho SH, Na KS. Haemangioendothelioma on the conjunctiva of the upper eyelid. Clin Experiment Ophthalmol 2006;34:794-6.

7. Cooper JG, Edwards SL, Holmes JD. Kaposiform haemangioendothelioma: case report and review of the literature. Br J Plast Surg 2002;55:163-5.

8. Hardisson D, Prim MP, De Diego JL, et al. Kaposiform hemangioendothelioma of the external auditory canal in an adult. Head Neck 2002;24:614-7.

9. Mac-Moune Lai F, To KF, Choi PC, et al. Kaposiform hemangioendithelioma: five patients with cutaneous lesions and long follow-up. Mod Pathol 2001;14:1087-92.

10. Mentzel T, Mazzoleni g, Dei Tos AP, Fletcher CD. Kaposiform hemangioendothelioma in adults. Clinicopathologic and immunohistochemical analysis of three cases. Am J Clin Pathol 1997;108:405-55.

11. Senturk N, Y'yldiz L, Aydin F, Eroglu L, Canturk T, Turanli AY. Kaposiform hemangioendothelioma in an adult with an unusual presentation.J Eur Acad Dermatol Venereol 2006;20:630-2.

12. Zamecnik M, Mikleova Z, Michal M. Kaposiform hemangioendothelioma in adult. Report of a case with amianthoid like fibrosis and telangiectases. Ceskoslov Patol 2000;36:163-7.

13. Bienaimé A, Rojat-Habib MC, Hesse S, Pelissier Jf, Bonerandi JJ. Giant vascular tumour in an adult: tufted angioma or kaposiform hemangioendothelioma.. Am Dermatol Venereol 2006;133:553-6.

14. P. Vashi, E. Abboud, C. Bier-Laning, and D. Gupta Adult-onset Kaposifor hemangioendothelioma of the tongue: case report and review of the literature. Curr Oncol. 2016 Oct;23(5): 517-520

15. Claudia S Vetter-Kauczok Philipp Ströbel ,Eva B Bröcker, Jürgen C Becker : Kaposiform hemangioendothelioma with distant lymphangiomatosis without an association toKasabach-Merritt-Syndrome in a female adult. Vascular Health and Risk Management 2008:4(1) 263-266.

16. Eduardo Maseda, a Rafael Blanco,a Armando Ablanedo,a and Eduardo Iglesias Oropharyngeal Kaposiform Hemangioendothelioma Acta Otorrinolaringol Esp. 2008;59(4):198-9.

17. Allan M. Concejero, Chao-Long Chen, Tai-Yi Chen, Hock-Liew Eng, and Fang-Ying Kuo, Kaohsiung, Giant cavernous hemangioma of the liver with coagulopathy: Adult Kasabach-Merritt syndrome. Surgery February 2009 ; Volume 145, Number 2 ; 245-7.

18. Min Geun Kim,Yoo Shin Choi, Sung Jun Park, Se Min Chong,Kaposiform Hemangioendothelioma of the Breast in an Adult Female. Clinical Breast Cancer, Vol. 11, No. 2, 135-7.

19. Felipe D'Almeida Costa, Andrew L Folpe Intratesticular kaposiform haemangioendothelioma in adults: a report of two cases. Clin Pathol 2013;66:623-626. doi:10.1136/ jclinpath-2013-201478.

20. Chien-Hui Wu, Tung-Ming Tsai, Jau-Yu Liau, Yih-Leong Chang, Hong-Shiee Lai, and Jang-Ming Lee: Expansile Kaposiform Hemangioendothelioma Deformed Thoracic Cage in an Adult .Ann Thorac Surg 2013;96:1854-7.

21. Wong BL, Dwivedi RC, Masterson L, Riffat F, Marker A, Jani P. Kaposiform hemangioendothelioma of paranasal sinus. Laryngoscope 2014;124:2103-6.

22. Ahmed A. Abdulrahman, Jie Yan, J. Steve Hou, Kaposiform hemangioendothelioma in an adult spleen: An unusual presentation. Human Pathology: Case Reports 10 (2017) 15-17.

23. Zivanit Ergaza, Benjamin Bar-Oza, Gilad W. Vainerb, Sinan Abu-Leila, Natalia Simanovskyc, Orna DiavCitrind Congenital fulminant Kaposiform hemangioendothelioma of the leg. Reproductive Toxicology 50 (2014) 
24. Takeo Nakaya, Kiyoko Morita, Atsushi Kurata, Tetsuo Ushiku,Takashi Igarashi, Masahiko Kuroda, Masashi Fukayama. Multifocal kaposiform hemangioendothelioma in multiple visceral organs: an autopsy of 9-day-old female baby. Human Pathology (2014) 45, 1773-1777.

25. Chu CY et al. Dermatology 2003; 206: 334-337.

26. Osio A et al. Arch Dermatol.2010; 146: 758-763.

27. J. May, A. Sadri , L. Shanks, S.H. Liew , B. Pizer, Kaposiform hemangioendothelium not just a bruise. JPRAS Open 1-2 (2014) 1-5.

28. Majdouline Boujoual, Fatima Jabouirik, Jaouad Kouach, Driss Moussaoui, and Mohammed Dehayni. Le Syndrome de Kasabach-Merritt: à propos d'un cas. International Journal of Innovation and Applied Studies ISSN 2028-9324 Vol. 9 No. 3 Nov. 2014, pp. 1349-1353.

29. Eriko Maedaa, Masaaki Akahane, Takeyuki Watadani, Naoki Yoshioka, Akiteru Goto, Yasuhiko Sugawara, Masatoshi Makuuchi, Kuni Ohtomoa. Isolated hepatic hemangiomatosis in adults: Report of two cases and review of the literature. European Journal of Radiology Extra 61 (2007) 9-14.

30. Beth A. Drolet, Lycia A. Scott, Nancy B. Esterly, and Arun K. Early surgical intervention in a patient with Kasabach-Merritt phenomenon. J Pediatr 2001;138:756-8.

31. Jiang RS, $\mathrm{Hu}$ R. Successful treatment of Kasabach-Merritt syndrome arising from kaposiform hemangioendothelioma by systemic corticosteroid therapy and surgery. Int J Clin Oncol. 2012;17(5):512-6.

32. Shao-yi Zhou, Hai-bo Li, Yue-ming Mao, Pei-ying Liu, Jing Zhang. Successful treatment of Kasabach-Merritt syndrome withtransarterial embolization and corticosteroids. Journal of Pediatric Surgery (2013) 48, 673-676.

33. Olivia Boccara. Phénomène de Kasabach-Merritt. Sang Thrombose Vaisseaux 2013 ; 25, no 2: 94-9.

34. R. Duclaux-Lorasa, A. Lachauxa, L. Guibaudb, Y. Bertrand. Is alfa-interferon still current in the management of Kasabach-Merritt syndrome? Archives de Pédiatrie 2015;22:523-527.

35. Marzanna Oksiuta, Ewa Matuszczak, Wojciech De bek, Ewa Dzienis-Koronkiewicz, Adam Hermanowicz. Successful exclusive propranolol therapy in an infant with life-threatening KasabacheMerritt syndrome. J Ped Surg Case Reports 1 (2013) 200-202.

36. Oza VS, Mamlouk MD, Hess CP, Mathes EF, Frieden IJ. Role of sirolimus in advanced kaposiform hemangioendotherlioma. Pediatr Dermatol.2016;33(2):e88-92. 